\title{
A RADICALIDADE DE OS PARCEIROS DO RIO BONITO
}

\section{Luiz Antonio C. Santos}

Uma técnica [...] quer dizer segurança, dominio do caos, afirmação de um caráter. E este caráter particular de uma obra é que a faz salvar-se do naufrágio do tempo, que determina a sua existência para além da sua época.

(Álvaro Lins, Jornal de Crítica, 1944)

I

Este texto tem um objetivo bastante limitado, que é situar a importância de uma única obra destacando-a do conjunto da produção de seu autor - para a ciência social brasileira. Os parceiros

* Texto apresentado no XXIV Encontro Anual da Anpocs, Petrópolis, 23 a 27 de outubro de 2000. Esta é uma primeira reflexão sobre a obra de Antonio Candido, que pretendo retomar em outro estudo. Cito desde já minha dívida com Mariza Peirano, com quem há tantos anos compartilho algumas das idéias aqui expostas. do Rio Bonito ${ }^{1}$ não provém da lavra de crítica literária de Antonio Candido, mas é, nitidamente, um trabalho de "cientista social". O procedimento de tomar Os parceiros à parte tem validade discutível, pois mesmo a produção propriamente literária de Candido tem importância marcante para além do campo literário, como revelou Bento Prado Jr., em trabalho sobre Cruz Costa. ${ }^{2}$ Os conceitos de formação, sistema e manifestações literárias, para ficar apenas nesses três, ajudam-nos, por exemplo, a entender a distinção entre o pensamento social pré e pós-1930, e tornam um tanto postiça a discussão em que, a esse respeito, se envolveram Florestan Fernandes e Guerreiro Ramos. Ainda assim, creio que vale a pena tentar, heuristicamente, fazer uma análise até certo ponto "isolada" de Os parceiros, pelos motivos que procurarei explicitar a seguir.

Mas antes, uma palavra introdutória sobre minha própria experiência ou convívio com a 
obra, um pouco anterior à minha entrada como estudante de graduação do Departamento de Sociologia da PUC/Rio, em 1967. Um acaso feliz me aproximara dos estudos de Antonio Candido desde moço, no interior de São Paulo. Quando migrei para o Rio de Janeiro, em 1965, havia lido, ou, francamente, "tentado" ler, alguns de seus artigos publicados na Revista de Letras da então Faculdade de Filosofia, Ciências e Letras de Assis, e no "Suplemento Literário" do jornal O Estado de S. Paulo. Quando ingressei no curso de sociologia, ainda inexperiente, tinha lido Os parceiros e creio que captara o essencial: havia muito mais naquele livro do que um estudo sobre o caipira paulista. (Superava de longe, diríamos hoje, os limites dos "estudos de comunidade".) Já lera também um ou outro "texto básico" de ciências sociais, da famosa coleção da Zahar Editores, e percebia que estava diante de um texto tão básico ou fundamental como os daquela coleção, lançada a partir de 1966. Iniciado o curso de sociologia, um ponto me intrigava: nos trabalhos de conclusão de curso em que citava Os parceiros, nunca obtinha um comentário, nem mesmo desfavorável. Era como se autor e obra fossem produto da imaginação de um aluno. Nos cursos em que aprendíamos (obsessivamente) método, ou naqueles que abordavam os fundamentos de sociologia, mudança social, capitalismo etc., havia algum lugar para Florestan Fernandes ou Costa Pinto, mas a onda estruturalista estourava sobre nossas cabeças e líamos sobretudo Althusser (mais do que Marx!) e os estruturalistas franceses. Só no quarto e último ano minha turma foi apresentada a Gilberto Freyre e Sérgio Buarque. ${ }^{3}$ A leitura deste último permitiu a alguns o contato com o (hoje bastante conhecido) Prefácio de Antonio Candido, sobre "O significado de Raizes do Brasil". ${ }^{4}$ Mas terminamos a graduação, estou certo, sem jamais termos ouvido uma palavra a respeito de Os parceiros. E, no entanto, tínhamos na Gávea talvez o melhor curso de sociologia do Brasil, se lembrarmos que o autoritarismo, havia pouco, fizera em pedaços os cursos de ciências sociais da USP e da "Nacional", no Rio de Janeiro.

Posso agora antecipar meu argumento. Para isso gostaria de lançar mão de um artigo esclare- cedor do crítico literário e professor de literatura, Antonio Lázaro de Almeida Prado - colega de Candido na Faculdade de Assis e, responsável, como ele, pela produção da Revista de Letras, uma revista de primeiro mundo em pleno "sertão" da Alta Sorocabana, há mais de quarenta anos. No artigo citado, chamou-me a atenção a noção de radicalidade discutida pelo autor. Almeida Prado atribui a Oswald de Andrade e Mário de Andrade uma radicalidade transformadora da literatura e da cultura brasileiras, aponta os fatores responsáveis por tal posição catalisadora, mas - este é o ponto fundamental - lembra que suas propostas estéticas só foram efetivamente assimiladas pelo "corpo social" décadas depois. ${ }^{5}$ Aqui me permito uma analogia. Discutirei mais adiante os significados da radicalidade de Os parceiros, e quero sugerir que, em que pese o grande número de trabalhos de cientistas sociais que a enaltecem, o real impacto da obra ainda não se fez sentir no interior da próprio campo. Estamos diante de louvações, de intenções, mas de resultados concretos hesitantes e esparsos sobre o produção das ciências sociais em nossos dias. O impacto reduzido se explicaria, a meu ver, por ser a obra de um crítico literário, visto como um outsider, sem relação com as importações consideradas legítimas, em geral restritas à filosofia (Althusser ontem, hoje Foucault/Deleuze). Outros poderiam sugerir uma segunda razão: o livro foi marcado por um "estigma de origem", que tanto naquele tempo como hoje equivaleria a um certificado de óbito: Os parceiros seria uma obra "funcionalista"... Ora, o próprio A. Candido refere-se, a certa altura do prefácio em que trata das influências intelectuais, à contribuição da abordagem "lúcida, embora simplificadora" do funcionalismo de Malinowski, para "estudar sociologicamente a alimentação humana”. Ou seja, trata-se de uma contribuição que "rende bem", num certo aspecto da vida social das famílias caipiras, mas o faz de modo simplificador. Por outro lado, minha geração aceitava, como as gerações recentes, o emprego da abordagem funcional por Florestan Fernandes, em seus clássicos sobre os Tupinambá. ${ }^{6}$ Não creio, portanto, ser este um motivo para a difusão tardia, entre as ciências sociais brasileiras, das lições contidas em Os parceiros. 
Não é este o lugar para vaticínios. (Quando, então, se fará sentir o impacto da obra?...) Quero aqui apenas alinhar algumas dimensões marcantes do texto, que denotam sua radicalidade íntima, constitutiva. São aspectos que lhe conferem, em primeiro lugar, permanência histórica, junto às novas gerações de cientistas sociais. Em segundo lugar, relevância intercultural - assim, por exemplo, quem quiser entender as questões agrárias do nordeste e não apenas do "interior paulista", terá sua visão aguçada pela leitura da obra, e terá uma visão retrospectiva que se projeta, heuristicamente, para o futuro.

\section{II}

O primeiro aspecto que lhe dá projeção duradoura resulta de um compromisso ético-político, de denúncia das condições de vida no campo e de crítica ao domínio oligárquico. Tantas obras de valor tiveram objetivo semelhante, mas não parecem ganhar viço com o passar do tempo. Entretanto, a tessitura fina de Os parceiros permite que o leitor penetre aos poucos na matéria social, até mesmo pelo estudo dos mitos e representações haja vista a discussão da "fome psíquica" do caipira -, para tocar fundo, por fim, nas raízes mesmas de produção da crise agrária, sem que para tal viagem ele seja conduzido por um tom raivoso de denúncia que daria ao texto uma feição particular, datada e localizada. Herbert Baldus captou bem este tipo de construção, de distanciamento parcial em relação ao objeto, ao prefaciar a dissertação de mestrado de Florestan Fernandes sobre os Tupinambá: "Há pessoas [...] para quem a miséria humana pode ser aliviada pela compreensão das forças que agem na sociedade" (grifo meu). Candido diz o mesmo com outras palavras, abrindo espaço para a crítica, ao dizer do "tom acadêmico" de sua obra e da posição política "apenas esboçada no fim" (Candido, 1964, p. 15). Ao meu ver, são justamente esses elementos de distanciamento que vão, como em um movimento pendular, permitir a leitura política do texto. Ora, para compor um texto neste molde sutil é preciso ter um amadurecimento em relação ao que aprende- mos a chamar de "instrumentos de análise". Muito da nossa sociologia de tempos passados fez uso apenas canônico ou litúrgico dos instrumentos de pesquisa e análise, servindo-se deles para descarregar uma denúncia sobre os leitores. Atualmente, as novíssimas gerações publicam copiosamente, pois o próprio cânone permite que se faça ciência social a toque de caixa, "dando-se a vOZ ao outro", e esquivando-se, propriamente, da construção do objeto. Nem mesmo os interacionistas simbólicos aceitariam legitimar procedimentos que negam validade ao próprio instrumento, em nome (de uma reificação) do "outro". Nesses termos, qual será o impacto de um livro como Os parceiros, onde as vozes dos caipiras são trabalhadas pela compreensão, e só por esse duro caminho metodológico se transformam em sujeitos da análise e provocam a indignação política?

O segundo aspecto do estudo é sua dimensão estética radical. Refiro-me aqui à contribuição formal, em que se destaca uma leve arquitetura da palavra, a opção clara pela simplicidade, pelo "princípio da economia de dicção". Impressiona que, sem abrir mão da utilização rigorosa dos conceitos da antropologia e da sociologia (ou talvez por isso mesmo), Candido jamais submete o leitor a uma carga pesada. Sabe-se que muitas vezes a alusão (ritual) a um conceito substitui sua aplicação concreta, como se vê em um número incontável de textos publicados em ciências sociais, em que os conceitos ficam apenas enunciados, sem de fato interferirem na análise. Mas atente-se: o estilo leve de Os parceiros, sua "elegância discreta”, como diria o poeta, não é trivial, não é fácil. Ao contrário, aqui reside o ponto fundamental de sua escrita, pois é uma simplicidade que se alcança trabalhando-se o texto. Não é uma simplicidade natural ou espontânea. A argumentação passa, portanto, por um filtro exigente, que depura os conceitos de seu peso, para, até certo ponto, recriá-los ou moldá-los de maneira transparente; os significados são oferecidos sem resistência ao leitor por meio de uma sintaxe burilada, mas singela. Já no início do livro (p. 10), podemos observar como os aspectos conceituais são apresentados de maneira límpida. Candido abre um tópico sobre a obtenção dos meios de subsistência e seu impac- 
to na sociabilidade, frisando dever-se a Marx a compreensão da "solidariedade profunda do mundo físico e da cultura humana”, para, em seguida, assinalar que foi Malinowski quem mais tarde mostrou que, "sendo uma das molas da cultura", a satisfação das necessidades "já se situa em pleno terreno institucional". Ou seja, no território das ciências sociais, na interface entre cultura e instituições humanas. Mais adiante, desfaz o emaranhado de um tema difícil, que é o do papel da alimentação nas representações mentais de uma população rústica. Para tanto, retoma a abordagem da dieta em Malinowski. Foi ele, afirma Candido, "certamente o primeiro a expor sistematicamente a sua importância social e cultural”, particularmente nos casos "em que a elaboração de uma dieta é problema cruciante, absorvendo os esforços do grupo e dando lugar a fenômenos de tensão psíquica" (Candido, 1964, p. 16, grifo meu). A partir daí, nos capítulos seguintes, o estudo vai justamente construir a etnografia das populações rurais mais antigas de São Paulo, lançando a trama fina, mas inteiriça, que vai integrar o mundo empírico e os conceitos. Enfatizo os adjetivos "fino" e "inteiriço" para o fio que tece todo o trabalho, pois não se encontrará neste, em momento algum, digressões esparramadas a respeito de um conceito; nem conceitos estéreis e desacompanhados, sem utilização concreta; nem dados brutos citados copiosamente; ou, ainda, material empírico órfão, à espera de conceituação. Ora, a busca da medida justa, que Os parceiros realiza com êxito, é tarefa difícil nas ciências sociais. Os muitos livros sobre método que temos à disposição, e que nossos alunos usam por vezes para encontrar receitas que possam eliminar o esforço penoso daquela busca, não podem de fato fazê-lo. Por outro lado, diria mesmo, quanto ao problema particular da forma, que hoje não se deseja o estilo direto e transparente, em grande parte porque nossos modelos filosóficos (à exceção talvez dos pragmatistas, et pour cause!) pautam-se numa dicção hermética, o que não se justifica sob a ótica da ciência social, para a qual o hermetismo é perfeitamente desnecessário. Entretanto, quais são as atuais condições para a formalização superior do estilo e para a maturação de uma argumentação lúcida? Não constituem tarefas fáceis para os cientistas sociais brasileiros. O uso copioso do jargão em nossos textos e as frases de pensamento tortuoso escondem, na verdade, a dificuldade crescente, que se observa claramente em nossos alunos, de manejar não apenas conceitos que exigem poda ou limpeza para serem manejados, mas a própria sintaxe (penso aqui nas ciências humanas como um todo, incluindo aí, hélas, a psicanálise).

A menção a outros campos do conhecimento permite-me chegar ao terceiro aspecto, que é talvez a pedra de toque do estudo e de sua brava resistência ao tempo: a contribuição metodológica. Uma metodologia em ato, que pede uma leitura atenta para captar a arquitetura do texto, a íntima articulação das partes e o destino dado, a cada passo, à proposta aparentemente simples exposta na seção sobre o "Método", breve e incisiva, em que Candido enuncia os pressupostos da análise (Candido, 1964, pp. 3-6). Aqui lanço mão de um ensaio de interpretação que o autor escreveu sobre Sérgio Milliet, intitulado "O ato crítico" (Candido, 1987, cap. 8). Utilizo, portanto, a crítica metodológica de Candido a outro autor, para apreender sua própria metodologia. No texto aludido, como em Os parceiros, defrontamo-nos com um pressuposto básico: a defesa do ato crítico como um movimento interpretativo aberto e pautado por alguma fluidez, em contraposição à adesão irrestrita a este ou aquele aparato teórico-conceitual. Desde logo, só esta aversão a camisas-de-força no plano dos conceitos explicará em grande medida por que Candido consegue realizar o trespassing de um a outro corpo teórico sempre que seu problema de pesquisa assim exigir. Nisto consiste o fundamento de sua radicalidade metodológica: a obra antecipa, em plena década de 1960 - período em que minha geração e alguns mestres associavam metodologia à lição doutrinária -, a possibilidade do ato interpretativo migrar legitimamente de um a outro corpo conceitual. Gostaria de frisar que assinalar tal possibilidade não é propô-la como receita. Candido não dá lições, mas revela caminhos possíveis. (Hoje em dia, a abertura de opções facilita o trespassing, mas sabemos que a adoção bem-sucedida de diferentes procedimentos na pesquisa exige destreza e maturidade intelectual.) 
Creio que a riqueza da proposta de Os parceiros está em resguardar o papel ativo do observador/intérprete, que toma decisões, faz escolhas, preserva sua autonomia em relação ao objeto para mais bem compreendê-lo. No artigo citado sobre Sérgio Milliet, Candido pondera, com um leve toque de ironia, que a intelegibilidade do objeto não exige que se anule a inteligência do sujeito (Candido, 1987, p. 131). Mas há uma atitude mental de empatia em relação ao outro, atitude criadora que se afasta de um frio e distante sociologismo construtivista, mas ao mesmo tempo desautoriza o sujeito imperial, que atribui ao objeto o caráter ou as características que "gostaria" que tivesse, conforme a ideologia ou as crenças que partilha. Tampouco o intérprete aceita mutilar-se, como sugeri anteriormente. Veja-se a forma pioneira com que emprega a técnica da história oral. No Apêndice temos a transcrição direta de lendas narradas por Nhô Roque Lameu, mas no corpo do texto (Candido, 1964, pp. 154-159) as falas deste e de outros moradores - todos analfabetos - são trabalhadas admiravelmente. Os problemas mais flagrantes da dura vida que as transformações do capitalismo rural thes impunham são captados através de depoimentos orais, e interpretados à luz da noção de um "saudosismo transfigurador". No passado possuíam pequenas glebas, mas as mudanças econômicas no meio rural os empurravam para a situação de foreiros, meeiros etc. Diante das dificuldades de reação ou adaptação às novas condições, os "parceiros" recorriam a representações compensatórias, em que o mundo antigo aparecia, nos depoimentos, como um tempo de fartura, de solidariedade e de sabedoria. Se parasse ali e acatasse as representações como retrato "objetivo" de uma época e de um lugar - à maneira de alguns trabalhos de história oral hoje em dia -, Candido estaria aceitando o que a historiografia regional e os próprios moradores mais velhos já em parte desmentiam: havia, é certo, elementos que a etnografia permitia corroborar (particularmente quanto às formas de solidariedade grupal, como o mutirão), mas havia também, claramente, manifestações de uma "utopia retrospectiva": "Os caipiras sabem que essa é uma imagem ideal, e na verdade havia mais mortes e violência, a maleita 'abria faia (falha) no povo', ocorriam anos de míngua e fome. [...] No entanto, é a sua maneira de criar uma idade de ouro para o tempo onde funcionavam normalmente as instituições fundamentais da sua cultura" (Candido, 1964, p. 156). A partir daí, a análise vai distinguir mitos de "recuperação" ou "superação", conforme as histórias contadas se pautem na possibilidade de resgatar o passado ou na de aderir ao "mundo estranho do homem da cidade". Focalizo mais de perto esta parte de elaboração conceitual das representações para enfatizar a proposta realmente antecipadora do emprego da técnica de história oral e o modo pelo qual se distancia, na verdade, do seu uso corrente, abundante e um tanto sem-cerimônia, pela ciência social internacional. As propostas de Candido afastam-se daquelas que, já na década de 1970 e atualmente mais em voga, busca(va)m explicar a práxis dos grupos sociais "por eles mesmos". Tampouco Os parceiros se inscreve na linha discursiva inquisitorial das décadas de 1960 e 1970, em que as "chaves da sociologia" na verdade fechavam as portas à imaginação criadora e instauravam um discurso hegemônico, calcado na desqualificação e na ocultação de linguagens rivais. A radicalidade metodológica do estudo está, portanto, na ausência de "manifestos", tão a gosto da época em que o livro foi escrito. E é radical também em relação aos tempos atuais: o estudo tem quadros de referência nítidos e a eles se apega de maneira coerente e sistemática, ainda que a análise possa transferir-se de um referencial teórico a outro. Não se trata de defender uma espécie de "vale tudo" metodológico: o texto de Candido demarca com clareza os limites entre o espírito crítico aberto e a conduta aventureira na pesquisa. Se há uma lição a tirar da "aventura sociológica" ou antropológica de Os parceiros para as novas gerações, é a necessidade de um esforço permanente de formação intelectual. A aventura, aqui, pressupõe um plano de viagem e a preocupação com a técnica de pesquisa, com o cuidado formal, com o cultivo de um espírito crítico e do olhar adestrado. Estamos de volta ao "ato crítico".

Estes são, talvez, os aspectos mais significativos para minha leitura de Os parceiros do Rio Bonito. Mas há um quarto ponto que gostaria de en- 
fatizar, e que não procede diretamente da análise do texto. A partir da leitura de um outro ensaio de Antonio Candido, ${ }^{8}$ julguei que, em um sentido muito preciso, fosse aceitável buscar em seu livro certos traços da conduta acadêmica e de sua vida intelectual. Para tanto, farei uma breve alusão a outros trabalhos de sua autoria. Mas não poderia fazê-lo se não houvesse - é esta minha leitura de seu ensaio sobre Sílvio Romero - a possibilidade heurística de estreitas correlações entre texto e conduta intelectual. O quarto aspecto que quero assinalar é, pois, produto do texto, mas, ao mesmo tempo, "afirmação de um caráter", no dizer de Alvaro Lins. A obra Os parceiros é indicativa de uma certa postura ética do autor diante do mundo acadêmico. Encerra uma lição de vida acadêmica. Mais ainda, é possível levantar-se a hipótese de que certos traços da conduta pessoal de um autor têm impacto sobre sua obra. Há, portanto, uma identidade virtual entre produção intelectual e traços de caráter do autor, entre os quais Candido singulariza, negativamente, a vaidade. Vamos ao que propõe, a respeito do grande crítico sergipano, da mesma geração de Joaquim Nabuco:

\begin{abstract}
Silvio Romero não policiava a sua vaidade nem renunciava ao prazer de falar de si a qualquer propósito. [...] Isso, desde moço. Ainda na casa dos trinta, e com o persistente mau gosto brasileiro nesse campo, já fazia com e sem propósito balanços da própria obra, proclamando as suas inovações, reivindicando o seu lugar na cultura nacional e até procurando comprovar que sabia alemão (Candido, 1987, p. 114).
\end{abstract}

Essas declarações, pondera Candido, têm um tom invariavelmente provinciano e chegam a atrapalhar a própria tarefa de avaliação da obra de Romero. Mas a hipótese a que me referi é mais explícita em outro estudo de $A$ educação pela noite, na passagem em que "Minha formação", de Joaquim Nabuco, tem seu "caráter exemplar" atenuado pela "personalidade bastante narcísica" de Joaquim Nabuco, "dando exemplo de como o dado pessoal pode se dissolver na vaidade, a mais particularizadora das forças que atuam em nós" (Candido, 1987, p. 53, grifos meus). Candido interessa-se pelo salto do local ao universal por meio da autobiografia, ou seja, pelas condições em que o "eixo universalizante" pode contrapor-se à expressão pessoal, datada, localizada. Sob este ponto de vista, o melhor livro brasileiro de memórias do século XIX foi, em sua opinião, Minhas recordações, do mineiro Ferreira de Resende, escritas entre 1887 e 1890 e só publicadas em 1944! Nas palavras de Candido:

Depois de Marilia de Dirceu, tomemos Minhas recordações como exemplo da capacidade demonstrada por tantos mineiros de, inserindo o eu no mundo, mostrar os aspectos mais universais nas manifestações mais particulares, num avesso da autobiografia estritamente individualista do tipo Nabuco, da qual o interesse [...] consiste em reduzir o geral à contingência do particular (Candido, 1987, p. 53-54, grifos meus).

Ou seja, a força particularizadora da vaidade contamina a feição individual ("filtro de tudo") e impede que a autobiografia possa traduzir-se em "heterobiografia", "história simultânea dos outros e da sociedade" (Candido, 1987, p. 56). Diria que, no caso dos estudos de ciências sociais, esta contaminação da expressão escrita pela personalidade narcísica pode revelar-se no conjunto da produção intelectual, comprometendo o vigor criativo que determina a permanência da obra para além da sua época. Posso agora retornar a Os parceiros. Ao redigir o prefácio ao livro, em 1964, Candido poderia perfeitamente arrolar suas publicações e citar o êxito de crítica, "lembrando ao leitor", na maneira constrangedora dos prefácios de Gilberto Freyre, seu lugar já marcante na cultura brasileira. ${ }^{9}$ Mas não o fez. Ao contrário, a atenção do autor concentra-se em demonstrar em que medida o trabalho, nascido como tese de doutorado, poderia ter sido aperfeiçoado, corrigidos certos equívocos, explicitada a posição política, "apenas esboçada no fim". Assinala ainda as influências intelectuais que recebeu durante as fases de pesquisa e de produção do texto. Que outras indicações necessitaria o leitor ou o crítico? Seria importante que soubesse da existência de outros estudos do autor sobre a organização social dos "parceiros", e para isso Candido cita-se uma única vez em todo o livro, ao reproduzir, na Parte Complementar, um pequeno estudo seu sobre a vida familiar do caipira. Esta atitude intelectual sóbria, avessa à auto- 
promoção, relaciona-se, a meu ver, com um certo tipo de sociabilidade respeitosa em relação a seus pares e aos leitores, uma postura ética que flui da vida para "dentro do texto", e, como lição, oferece-se à sociabilidade e à produção acadêmicas. Anteriormente revelei o reparo feito por Candido ao provincianismo de Romero. Agora posso indicar como sua atitude crítica se casa com sua ética pessoal ao procurar pontos fortes na personalidade do outro e reduzir as referências pessoais ao essencial. Romero é recuperado, então, em seu ritmo humanamente contraditório: "a atitude correta é não ir na provocação do seu temperamento polêmico; não querer, por exemplo, reduzi-lo às suas contradições nem proclamar a sua perfeita unidade; e sim procurar entender o seu ritmo de turbilhão. Na verdade a contradição era o seu modo próprio de viver o pensamento" (Candido, 1987, p. 102).

Retorno ao argumento inicial para modificálo em parte. Disse que o livro Os parceiros encerra uma radicalidade que o tornou, em sua época (como em nossos dias, talvez menos pelo aspecto metodológico), dificilmente assimilável pelas ciências sociais brasileiras. A menção ao quarto aspecto, até certo ponto "fora da obra" e relativo à conduta intelectual do autor - um traço pessoal de caráter - coloca um desafio diferente, que poderia ser traduzido em "valor ético de base", ${ }^{10} \mathrm{em}$ atitude diante da atividade acadêmica ou intelectual. Quantos de nós passaremos por este crivo, e por quanto tempo? Estamos diante de uma proposta de um "modo de ser" que dificilmente encontrará guarida, mesmo junto às velhas gerações como a minha, diante da competição atlética em que se transformou a vida acadêmica, no Brasil e no exterior. Mas algo já brotou e frutificou, e não há como voltar atrás: Candido inspirou um grupo de intelectuais em São Paulo e em outras regiões do país, formados em uma atmosfera sem autoritarismo pessoal, descobrindo e reforçando as qualidades intelectuais de quem dele se aproximava. A sociabilidade e a auto-estima convivem, aqui, de modo a enriquecer a vida intelectual. Daí posso sugerir que não só Os parceiros do Rio Bonito, mas todos os ensaios referidos, encerram uma radicalidade ética e brotam de uma prática de convivência marcada pela cordialidade e pela civilidade. Com o tempo, a reverência que hoje desfruta o nome do professor Antonio Candido nas ciências sociais brasileiras deverá dar lugar à referência a Os parceiros do Rio Bonito, sua obra singela e monumental.

\section{NOTAS}

1 Utilizo a primeira edição de Os parceiros do Rio Bonito (1964).

2 Bento Prado Jr. (1986); ver especialmente as páginas 103 a 110, onde a discussão conduz a este fecho explicativo: "na realidade, havia alguma coisa que faltou na minha leitura de Antonio Candido [e] na minha leitura do Foucault, principalmente na do Antonio Candido, que eu acho que é um historiador da cultura um pouco mais fino do que [...] Foucault" (grifo meu).

3 Por indicação de Bolívar Lamounier, em passagem rápida, mas marcante, pelo Departamento de Sociologia da PUC do Rio de Janeiro.

4 Foi nesse prefácio que Candido pôs em primeiro plano Sérgio Buarque, Gilberto Freyre e Caio Prado Júnior, como demarcadores de novas fronteiras no campo intelectual brasileiro. Há quem diga que teria sido injusto em relação a Oliveira Viana, suposição a meu ver equivocada. Candido emitiu um juízo correto, ao lamentar a marca do preconceito e os excessos doutrinários na obra do intelectual fluminense, ainda que "por tantos aspectos penetrante e antecipadora".

5 Remeto o leitor ao texto de A. L. de Almeida Prado, "No país dos Andrades: Miramar e Macunaíma - radicalidade na arte e na práxis", Revista de Letras, 17: 205-230, 1975.

6 Ainda estudante de sociologia, pedi-lhe certa vez que autografasse meu exemplar de Os parceiros, ocasião em que lhe contei que um colega mais velho - que mal conhecia o livro - me havia "alertado" sobre seu suposto funcionalismo. Logo em seguida li a dedicatória: "Ao Luiz Antonio, com o abraço funcionalista do Antonio Candido". Mostreia mais tarde ao colega, que enrubesceu.

7 Faço uso outra vez das sugestões de Almeida Prado, op. cit., pp. 212 e 219.

8 Trata-se de seu estudo sobre a obra e a vida pública de Sílvio Romero, reproduzido em $A$ educação pela noite \& outros ensaios com o título "Fora do texto, dentro da vida".

9 A rigor, o grande narciso de Apipucos sempre procurava ofuscar seus leitores com o brilho estelar 
conquistado no mundo. Este Freyre provinciano nunca se permitiu desfrutar a tranqüilidade intelectual de quem produziu, de fato, pelo menos duas das maiores obras do pensamento social brasileiro desde 1930: Casa-grande E senzala e Nordeste.

$10 \mathrm{Na}$ expressão de Davi Arrigucci Jr., empregada em outro contexto; ver Arrigucci, 1987, p. 17.

\section{BIBLIOGRAFIA}

ALMEIDA PRADO, A. L. de. (1975), "No país dos Andrades: Miramar e Macunaima - radicalidade na arte e na práxis". Revista de Letras, 17: 205-230, Faculdade de Filosofia, Ciências e Letras de Assis

ARRIGUCCI JR., Davi. (1987), Enigma e comentário: ensaios sobre a literatura e experiência, São Paulo, Companhia das Letras.

CANDIDO, ANTONIO. (1964), Os parceiros do Rio Bonito. Rio de Janeiro, José Olympio Editora (Coleção Documentos Brasileiros).

. (1987), A educação pela noite \& outros ensaios, São Paulo, Ática.

PRADO JR., Bento. (1986), "Cruz Costa e a história das idéias no Brasil", in Reginaldo Moraes et al. (orgs.), Inteligência brasileira, São Paulo, Brasiliense.

RESENDE, Ferreira de. (1944), Minhas recordações. Rio de Janeiro, José Olympio (Coleção Documentos Brasileiros, 45). 


\section{A RADICALIDADE DE OS PAR- CEIROS DO RIO BONITO}

\author{
Luiz Antonio C. Santos
}

\section{Palavras-chave}

Teoria social; Antonio Candido; Interdisciplinaridade; Metodologia de pesquisa

O livro Os parceiros do Rio Bonito traz uma contribuição admirável ao pensamento social brasileiro por sua relevância ético-política, como obra de denúncia política e crítica social; por sua contribuição formal ou estética, uma fina arquitetura da palavra e da argumentação sociológica e antropológica; e por sua contribuição metodológica, a pertinência do ato crítico aberto e pautado pela fluidez, em contraposição à adesão irrestrita a determinado aparato teórico. À atitude crítica associa-se a atitude mental de empatia pelo objeto, que se afasta de um frio e distante "sociologismo", mas, ao mesmo tempo, se recusa a atribuir-lhe as características que "gostaríamos" que tivesse, conforme a ideologia ou as crenças que partilhamos. A radicalidade dessa obra reside no espírito aberto para a "aventura sociológica", daí resultando a inexistência de "manifestos" ou "normas" de conduta. Todavia, Candido demarca os limites entre o espírito aberto à diversidade e à versatilidade no trato do fenômeno social, de um lado, e a adesão aventureira a um relativismo estéril, de outro. Finalmente, discute-se aqui a íntima relação entre a conduta intelectual do autor - sua postura ética diante do mundo acadêmico - e sua própria obra.

\section{THE RADICAL ASPECT OF OS PARCEIROS DO RIO BONITO}

Luiz Antonio C. Santos

\section{Keywords}

Social theory; Antonio Candido; Interdisciplinary; Research methodology

The book Os Parceiros do Rio Bonito brings an admirable contribution to the Brazilian social thought for its ethic-political relevance as a work of political denounce and social criticism, for its formal or aesthetic contribution, a fine architecture of words and sociological and anthropological arguments; and also for its methodological contribution, the pertinence of an open critical act marked by flow, in contrast with the unrestricted adhesion to certain theoretical apparatus. Added to the critical attitude is the attitude of empathy for the object, that stands back from a cold and distant "sociology" but, at the same time, it refuses to attribute the characteristics that "we would like" to hear, according to the ideology or beliefs that we share. The radical aspect of this work is in the free spirit for a "sociological adventure" and, as a result, "manifestos" or "norms" of conduct are absent. Yet Cândido marks the limits between the spirit opened to diversity and the versatility in the treatment of the social phenomenon and the adventurous adhesion to a sterile relativism. Finally, the article discusses the intimate relationship between the author's intellectual conduct - its ethical position within the academic world - and its own work.

\section{LE CARACTÈRE RADICAL DE OS PARCEIROS DO RIO BO- NITO}

\author{
Luiz Antonio C. Santos
}

\section{Mots-clés}

Théorie sociale; Antonio Candido; Interdisciplinarité; Méthodologie de recherche

Le livre Os parceiros do Rio Bonito constitue un apport admirable à la pensée sociale brésilienne, par son importance éthique et politique, comme une oeuvre de dénonciation de la politique et de la critique sociale; par sa contribution formelle ou esthétique, une fine architecture du mot et de l'argumentation sociologique et anthropologique; et par sa contribution méthodologique, la pertinence de l'acte critique ouvert et marqué par la fluidité, en contrepoint à l'adhésion sans restrictions à une base théorique déterminée. L'attitude critique s'associe à l'attitude mentale d'empathie par l'objet, qui s'éloigne d'un froid et distant "sociologisme" mais qui, en même temps, refuse de lui attribuer les caractéristiques que nous "aimerions" qu'elle eût, selon l'idéologie ou les croyances que nous partageons. La radicalisation de cette oeuvre réside dans l'esprit ouvert vers une "aventure sociologique", dont résulte l'inexistence de "manifestations" ou de "règles" de conduite. Candido démarque, néanmoins, les limites entre l'esprit ouvert à la diversité et à la versatilité dans l'abordage du phénomène social d'un côté, et de l'adhésion aventurière à un relativisme stérile de l'autre. Finalement, nous discutons l'étroite relation entre la conduite intellectuelle de l'auteur - sa posture éthique face au monde académique - et sa propre oeuvre. 